\title{
Better the second time around? Department of Justice Registered Intermediaries Schemes and lessons from England and Wales
}

\author{
PENNY COOPER
}

Kingston University

and

DAVID WURTZEL

City University ${ }^{1}$

\begin{abstract}
$\underline{\text { Abstract }}$
In 2012 the Department of Justice (DoJ) Northern Ireland recruited and trained a cohort of Registered Intermediaries in preparation for the commencement in 2013 of pilot schemes to assist vulnerable witnesses and defendants to communicate their evidence. This article reviews the history of intermediaries and critically analyses the lessons learnt from the Ministry of Justice (MoJ) Witness Intermediary Scheme (WIS) operating in England and Wales over the last decade. It compares the schemes which, though similar, are distinct and significantly different in respect of defendants and suggests what more is required in Northern Ireland in order to support the introduction of Registered Intermediaries.
\end{abstract}

\section{Introduction}

Our languages of communication are rough-hewn devices, sometimes coarse and sometimes marvellously subtle, reflecting insights and purposes of past cultures, which in part continue to be vital to the present, but in part to be alien and irrelevant. ${ }^{2}$

$\mathrm{O}$ n 13 May 2013 the DoJ Northern Ireland launched the Registered Intermediaries Schemes (RIS) pilot to assist vulnerable witnesses and defendants to communicate with those in the criminal justice system who question them. In England and Wales the MoJ WIS began to help witnesses early in 2004. It is available in all criminal courts throughout England and Wales. The WIS has provided a template but not a blueprint for Northern Ireland. The English and Northern Irish schemes operate independently of one another. Though they share a common purpose, those intermediaries accredited in one jurisdiction are not accredited in the other.

1 Professor Penny Cooper and David Wurtzel work with the DoJ (Northern Ireland) and the MoJ (England and Wales) teaching and advising Registered Intermediaries; they also co-author the procedural guidance manuals for Registered Intermediaries. This article is based on their paper 'Victims and Vulnerable Witnesses in the Criminal Process' (Criminal Bar Association Conference, Belfast, 12 May 2012). The authors are particularly grateful to Norma Dempster at the DoJ for her assistance with this article. Thanks are also due to the anonymous reviewer of the draft article and to Jason Connolly and Joyce Plotnikoff for their comments on the earlier conference paper. The usual caveat applies.

2 S S Tomkins, 'The Varieties of Shame and its Magnification' in E Virginia Demos (ed), Exploring Affect: The Selected Writings of Silvan S Tomkins (CUP reprinted 2004) 397. 
In August 2012 the DoJ advertised for individuals to take part on a self-employed basis ${ }^{3}$ in its RIS pilot 'to assist vulnerable witnesses and vulnerable defendants to communicate effectively during the police investigation and any subsequent trial'. ${ }^{4}$ Initially the pilot schemes have operated in the Belfast Crown Court for offences that are triable only on indictment and that have occurred in the Belfast district council area. After three months the DoJ had received just 12 requests for a Registered Intermediary so it was decided to extend the scope of the pilot to all Crown Courts from 11 November 2013 in order to have sufficient numbers to evaluate the pilot effectively. Following evaluation of the pilot it is envisaged that the RIS will be rolled out across further court tiers. ${ }^{5}$

The DoJ sought applicants for Registered Intermediaries 'from a wide background of professional roles and occupations, including speech and language therapy, occupational therapy, psychology, social work, the mental health professions, counselling, teaching and nursing ${ }^{6}$ who would bring the skills and experience gained in these roles to their work as a Registered Intermediary. Over 150 people applied. Those who were selected took part in an intensive training and assessment course ${ }^{7}$ consisting of a distance learning module, six days of training and four assessments covering legal procedure, report writing, the role and responsibilities of the intermediary and court work with a witness. ${ }^{8}$ Registered Intermediaries from England travelled to Belfast and gave delegates the benefit of their experience; the group met members of the local judiciary and the Northern Irish Bar and they were able to use the actual court and witness facilities at Laganside for role-play training. In January 2013, 11 were assessed as having successfully completed the course.

The DoJ provision differs in some key respects from the MoJ's. In both jurisdictions Registered Intermediaries can assist prosecution or defence witnesses. However, in Northern Ireland vulnerable defendants, when giving evidence, will also be able to take advantage of the statutory scheme. In England and Wales there is parallel legislation which would allow that but it has not yet been brought into force. There are lessons to be learnt from the WIS but as regards Registered Intermediaries for defendants, the RIS will be breaking new ground.

\section{History}

Until relatively recently, the courts have been left to make proper allowances on an ad hoc basis in order to allow children and other vulnerable witnesses to give evidence, assuming that they were allowed to at all. A general view prevailed in respect of children that they made unreliable witnesses ${ }^{9}$ and there was a tendency to treat children 'almost as if they were a different species'. ${ }^{10}$ As recently as October 1986 the English Court of Appeal in $R v$

3 Fees, which are reviewed annually, are payable at $£ 36.00$ per hour, $£, 16.00$ per hour for travel with an unsocial hours rate of $£, 52$ per hour. Source: DoJ Application Information Pack (August 2012) 7.

4 Ibid 2.

5 By mid-March 2014, under the pilot scheme, the DoJ had received in total 106 requests for assistance from a Registered Intermediary. Of these, four were assessed as not requiring a Registered Intermediary: information supplied by the DoJ by email to the authors, March 2014.

6 DoJ (n 3) 3.

7 Run by Kingston University London, designed and led by the authors.

8 An oral assessment carried out with an actor using Belfast Crown Court live-link facilities.

9 'The [psychology] studies from the beginning of this century which support this gloomy view ... have now been widely criticised.': John Spencer and Rhona Flin, The Evidence of Children: The Law and Psychology (2nd edn OUP 1990) 286.

10 Ibid 287. 
Wright and Ormerod ${ }^{11}$ affirmed the 'validity of, and good sense' of the established proposition set out in $\mathrm{R} v$ Wallwork $^{12}$ that 'the jury could not attach any value to the evidence of a child of five: it is ridiculous to suppose they could'. The rule by which juries had to be given a warning about convicting the accused on the uncorroborated evidence of a child was not abolished in both jurisdictions until 1988. ${ }^{13}$ There are no comparable dicta in respect of vulnerable adults. Until relatively recently scientists and doctors (let alone police officers and lawyers) had a limited understanding of conditions which can affect communication and could make adults and children vulnerable when questioned. For instance, dyslexia, ${ }^{14}$ Alzheimer's disease ${ }^{15}$ and autism ${ }^{16}$ were identified less than 150 years ago and Asperger syndrome ${ }^{17}$ was not identified until some 60 years ago. Today policymakers and law-makers endeavour to find ways to assist those with speech, language and communication needs ${ }^{18}$ but it was not until well into the twentieth century that the courts began to consistently make adjustments to take into account communication difficulties.

On 20 June 1988 the then Home Secretary, Douglas Hurd, MP, announced in the House of Commons the establishment of an advisory group to consider the use of video recordings as a means of taking the evidence of children and other vulnerable witnesses at criminal trials. He cited a growing body of support for change which had manifested itself during the passage of the Criminal Justice Bill. The chair of that advisory group was HHJ Thomas Pigot QC, the Common Serjeant of London. 'The Pigot Report'19 in December 1989 recommended that at trials on indictment for violent and sexual offences and offences of cruelty and neglect and at comparable trials in the juvenile courts (now the youth courts), video-recorded interviews with children under the age of $14^{20}$ conducted by police officers, social workers or those whose duties include the investigation of crime or the protection of the welfare of children should be admissible as evidence.

The advisory group went on to recommend pre-recorded cross-examination: there should be a preliminary hearing at which the child should watch the video recording, be asked to adopt it and to expand upon any aspects which the prosecution wishes to explore, and then to be cross-examined by the defence. This should happen outside the courtroom in informal surroundings and be video-recorded and in due course played to the jury. 'No child witness to whom our proposals apply should be required to appear in open court during a trial unless he or she wishes to do so', the Pigot Report stated. Pre-recorded cross-

11 [1990] 90 CAR 9.

12 [1958] 42 CAR 153.

13 S 34(2) Criminal Justice Act 1988 in England and Wales and Article 13 Criminal Justice (Evidence, etc) (Northern Ireland) Order 1988 in Northern Ireland.

14 Identified by Oswald Berkhan in 1881, though the term was first used by Rudolf Berlin in his 1887 paper 'Eine besondere Art der Wortblindheit-Dyslexie'.

15 Identified by Alois Alzheimer in 1907.

16 Identified by Eugen Bleuler in 1911 but until at least the 1950s the medical professional usually diagnosed autism as a psychosis. Autism Spectrum Disorder or Autism Spectrum Condition (ASD or ASC) is now widely used as an umbrella term.

17 Asperger Syndrome, a form of autism, is named after the scientist Hans Asperger who identified it in 1944. Leo Kanner is also credited with having identified it in 1943.

18 The Bamford Review of Mental Health Learning Disability (Northern Ireland 2007); The Bercow Report: A Review of Services for Children and Young People (0-19) with Speech, Language and Communication Needs (DoE 2008); Not a Marginal Issue: Mental Health and the Criminal Justice System in Northern Ireland (Criminal Justice Inspection Northern Ireland (CJINI 2010); Autism Act (NI) 2011; and the consequent NI Department of Health 2012 consultation on autism services in Northern Ireland and the consultation Getting it Right for Victims and Witnesses (MoJ 2012) to give but a few examples.

19 Judge Thomas Pigot QC, Report of the Advisory Group on Video Evidence (Home Office 1989).

20 Under 17 if the offence is of a sexual nature. 
examination has not yet happened in England and Wales, ${ }^{21}$ however, in June 2013 the MoJ announced the government's plan to pilot pre-trial cross-examination for vulnerable and intimidated witnesses 'by the end of the year in three Crown Court locations - Liverpool, Leeds and Kingston-Upon-Thames'. ${ }^{22}$ The Pigot Report also recommended that 'an adult person who is likely to suffer an unusual and unreasonable degree of mental stress by giving evidence in open court should be treated as a vulnerable witness'.

In England the Criminal Justice Act 1991 allowed children's interviews to be recorded and for the recording to be admitted as their evidence in chief. In order to provide good practice guidance for those conducting these interviews, in 1992 the Home Office and Department of Health published the 'Memorandum of Good Practice on Video Recorded Interviews with Children Witnesses for Criminal Proceedings'.23 Article 20 of the Criminal Justice (Children) (Northern Ireland) Order 1998 allowed a child to give evidence unsworn and provided that the child's evidence 'shall be received unless it appears to the court that the child is incapable of giving intelligible testimony'. The concept of the 'vulnerable witness' took root in the report Speaking up for Justice, ${ }^{24}$ which in turn led to the Youth Justice and Criminal Evidence Act 1999 and in Northern Ireland the Criminal Evidence (Northern Ireland) Order 1999 (the 1999 Order) and their identical ranges of special measures for children and vulnerable adult witnesses. 'Achieving Best Evidence' guidance (which replaced the Memorandum and quickly became known simply as ABE) was developed as part of the implementation of special measures and Northern Ireland and England and Wales have their respective versions. 25

\section{The current position}

The 1999 Order recognises that certain witnesses are 'vulnerable' and makes them 'eligible for assistance on the grounds of age or incapacity'. ${ }^{26}$ These special measures do not apply to the defendant. ${ }^{27}$ What is available to defendants will be discussed below separately.

The Article 11-18 special measures are:

Article 11: the witness, while giving testimony or being sworn in court, is prevented by means of a screen or other arrangements from seeing the accused

21 S 28 of the 1999 Act provides for cross-examination of the witness, and any re-examination, to be recorded by means of a video recording but has not yet been brought into force. See J R Spencer and M E Lamb, Children and Cross-Examination: Time to Change the Rules? (Hart Publishing 2012). In January 2013 the DPP for England and Wales said 'further consideration needs to be given to how best to implement section 28' when making a press statement on the report of Alison Levitt QC on the Savile cases <www.cps.gov.uk/news/press_statements/dpp_statement_about_savile_cases> accessed 22 January 2013.

22 'The pilots will run for six months followed by an assessment period after which we will consider how best to take this measure forward.' Written Ministerial Statement dated 13 June 2013 on 'Pre-trial Crossexamination testing'.

23 Memorandum of Good Practice on Video Recorded Interviews with Children Witnesses for Criminal Proceedings (Home Office/DoH 1992).

24 Speaking up for Justice: Report of the Interdepartmental Working Group on the Treatment of Vulnerable or Intimidated Witnesses in the Criminal Justice System (Home Office 1998).

25 Achieving Best Evidence in Criminal Proceedings: Guidance on Interviewing Victims and Witnesses, the Use of Special Measures and the Provision of Pre-trial Therapy (DoJ 2012) and Achieving Best Evidence in Criminal Proceedings: Guidance on Interviewing Victims and Witnesses, and Guidance on Using Special Measures (MoJ 2011).

26 Article 4 of the Criminal Evidence (Northern Ireland) Order 1999 mirrors the provisions of the 1999 Act. Note that other articles/sections of the 1999 Order/Act provide special measures for 'intimidated' witnesses but the intermediary is not available to them.

27 The accused is specifically excluded from eligibility for the special measures set out in this part of the legislation; see Article 5 of the 1999 Order and s 16 (1) of the 1999 Act. 
Article 12: the witness gives evidence by means of live link

Article 13: evidence is given in private (by excluding people from the courtroom)

Article 14: the wearing of wigs or gowns is dispensed with during the witness's evidence

Article 15: the admission of the witness's video-recorded interview as evidence in chief

Article 16: the admission of video-recorded cross-examination or reexamination

Article 17: the examination of the witness through an intermediary

Article 18: the use of aids to communication

Apart from Article 16 (incorporating the Pigot Report proposal of video-recorded crossexamination or re-examination) they are all in force. ${ }^{28}$ Article 17, commenced in 2013, states:

A special measures direction may provide for any examination of the witness (however and wherever conducted) to be conducted through an interpreter or other person approved by the court ('an intermediary'). The function of the intermediary is to communicate to the witness, questions put to the witness, and to any person asking such questions, the answers given by the witness in reply to them, and to explain such questions or answers as far as necessary to enable them to be understood by the witness or person in question. ${ }^{29}$

A witness is eligible for the assistance of an intermediary if they satisfy the test in Article 4 of the 1999 Order: 30

(1) A witness in criminal proceedings (other than the accused) is eligible for assistance by virtue of this section (a) if under the age of 17 [now 18] at the time of the hearing; or (b) if the court considers that the quality of evidence given by the witness is likely to be diminished by reason or any circumstances falling within subsection (2).

(2) The circumstances falling within this subsection are (a) that the witness (i) suffers from mental disorder within the meaning of the Mental Health (Northern Ireland) Order 1986; or (ii) otherwise has a significant impairment of intelligence and social functioning; (b) that the witness has a physical disability or is suffering from a physical disorder.

Article 4(5) of the $1999 \operatorname{Order}^{31}$ states:

(5) In this Chapter references to the quality of a witness's evidence are to its quality in terms of completeness, coherence and accuracy; and for this purpose 'coherence' refers to a witness's ability in giving evidence to give answers which address the questions put to the witness and can be understood both individually and collectively.

28 Apart from Article 16 and Article 17, they came into operation in respect of persons under 17 on 30 June 2003. Apart from Articles 15 (examination in chief by live link), 16 and 17, provisions relating to adult witnesses came into operation on 8 November 2004 in summary proceedings before the magistrates' court and on 21 December 2004 in criminal proceedings before the county court. Article 15 came into operation in July 2009 for adult witnesses in summary proceedings before the magistrates' court. Such a distinction between adults and children was not made in England and Wales. In England and Wales special measures became available in July 2002 apart from examination of a witness through an intermediary and videoed crossexamination or re-examination.

29 Article 17 of the 1999 Order mirrors s 29 of the 1999 Act.

30 S 16 of the 1999 Act uses the same wording except it refers to the Mental Health Act 1983.

31 S 29(5) of the 1999 Act uses the same wording. 
Note that children are eligible by virtue of age alone. Whether or not they require the assistance of an intermediary depends on the circumstances of the individual child; they may or may not be suffering from a disability or disorder; their communication needs may in fact relate simply to their age. The younger the child is, the greater the likelihood that an intermediary will be necessary to ensure developmentally appropriate communication. In England there have now been trials with children aged three or four giving evidence. ${ }^{32}$

Other countries use 'intermediaries' but quite differently. In South Africa, since 1993, they assist child witnesses in cases of sexual abuse 'for reasons of youthfulness or emotional vulnerability'. The child gives evidence via the intermediary in a separate room which is linked to the courtroom by closed-circuit television. The child does not see or hear anything that happens in court but the court can see and hear what happens in the live-link room. The intermediary, who is generally a social worker who prepares the child for the court appearance, hears the question through earphones. The intermediary translates questions for the child into suitable language but without changing the purpose of the question. ${ }^{33}$ There is no government training or oversight. There are jurisdictions (such as Austria, Norway and Israel) where the questioning of children has been taken out of the hands of the advocates and given to experts or the judge. In 2011, in a New Zealand report, 34 consideration was given to three different intermediary models using mock examinations. The Northern Irish/English model is unique.

It was noted even before the legislation was brought into effect that the 1999 Act and Order do little to define the intermediary's role: the Act 'gives no hint as to the identity of the intermediary' 35 nor whether the intermediary 'must have some form of formal qualifications or ... be completely independent of the witness and disinterested in the proceedings'. ${ }^{36}$ There was conjecture that the intermediary would perform 'a relatively passive "translator" function, "reinterpreting" lawyers' complex language into a more developmentally appropriate and therefore accessible form'. ${ }^{37}$ It was said that, since the legislation did not restrict the intermediary to acting purely as a conduit, 'the task of having to adjudicate disputes between the questioner and the intermediary will be unenviable'. ${ }^{38}$ These fears turned out to be unfounded because the Registered Intermediary became a facilitator, transparently advising the police and courts and intervening in the event of miscommunication usually to advise the questioner how better to communicate with the witness. The introduction of the new 'ground rules hearing' (discussed below) became crucial to the effective use of intermediaries and proper questioning of vulnerable witnesses.

32 See R Marchant, 'How Young is Too Young? The Evidence of Children under Five in the English Criminal Justice System’ (2013) Child Abuse Review <www.wileyonlinelibrary.com> DOI: 10.1002/car.2273.

33 G Jonker and R Swanzen, 'Intermediary Services for Child Witnesses Testifying in South African Criminal Courts' (2007) 4(6) SUR - International Journal on Human Rights 91-114.

34 E Davies, K Hanna, E Henderson and L Hand, Questioning Child Witnesses: Exploring the Benefits and Risks of Intermediary Models (Institute of Public Policy, AUT University 2011). In the model thought to be most effective, dubbed the 'topic by topic model', the intermediary is briefed by both counsel before trial on which aspects of the child's testimony they want explored and tested, puts the questions, then refers back to the lawyer for further instructions before moving on to the next topic.

35 K McEwan, 'In Defence of Vulnerable Witnesses: The Youth Justice and Criminal Evidence Act 1999' (2000) 4(1) International Journal of Evidence and Proof 1-30, 11.

36 L Hoyano, 'Variations on a Theme by Pigot: Special Measures Directions for Child Witnesses' (2000) 4 Criminal Law Review 250-73, 271.

37 L Ellison, 'Cross-examination and the Intermediary: Bridging the Language Divide?' (2002) 2 Criminal Law Review 114-27, 116

38 Hoyano (n 36) 272. 
The first MoJ intermediaries were trained in England in the autumn of 2003. The Home Office (prior to the creation of the Ministry of Justice in 2007) selected potential Registered Intermediaries who were already experts in communication in their own professional practice areas. ${ }^{39}$ They were taught relevant criminal law and procedure on a week-long university training course. ${ }^{40}$ They were taught that they must be impartial and neutral, that their paramount duty was to the court ${ }^{41}$ and that they were bound by a Code of Practice and Code of Ethics. ${ }^{42}$ It was of fundamental importance that they understood they were not witness supporters. That they were there to assist the administration of justice and not the vulnerable individual represented an important new professional perspective for many. They were trained in court practice and in writing a court report ${ }^{43}$ based on their assessment of the witness and their communication needs.

The six pathfinder areas began to operate in 2004 but the take-up was uneven between areas. Police officers discovered that the involvement of a Registered Intermediary could make the difference between a prosecution going ahead and not. A report on the pathfinder projects ${ }^{44}$ was produced in 2007 for the MoJ. It tracked 102 cases, 27 of which had ended after a suspect had been charged. It was considered by participants that at least half of the trial cases would not have reached the trial stage without the Registered Intermediary's involvement. Other conclusions were that almost all those who encountered the work of Registered Intermediaries in pathfinder cases expressed a positive opinion of their experience and provided specific examples of their contributions. Benefits included assisting in bringing offenders to justice, increasing access to justice, contributing to cost savings, assisting in identifying witness needs and informing appropriate interviewing and questioning techniques. Challenges to the use of Registered Intermediaries were due to poor levels of awareness, misinterpretation of the eligibility criteria, overestimating advocates' competence and underestimating the extent of communication difficulties. In 2007, the MoJ began to roll out the scheme nationally. This also involved devolving the cost of the scheme to local police and Crown Prosecution Service (CPS) areas. Awareness of the scheme and of its benefits increased, so did the use of Registered Intermediaries by police forces and CPS areas.

The most important function of the intermediary is to make sure that the vulnerable witness is questioned in a way that is appropriate to their ability to answer: 'quality in terms of completeness, coherence and accuracy', as per the 1999 Act (and the 1999 Order) or 'giving their best evidence' in everyday legal parlance. The statute does not expressly grant the right to the intermediary to intervene during the questioning but from the start, including during the very first intermediary training course, the right to intervene was taught as an essential part of their function. Intermediaries were also taught to recommend 'ground rules' in their reports to court and to request a ground rules hearing (or meeting) with the trial judge and advocates so that best questioning practice could be agreed. They were taught that interventions would normally be based on the agreed ground rules, that is

39 The majority of MoJ Registered Intermediaries are speech and language therapists. However, Registered Intermediaries also come from a wide background of professional roles and occupations including occupational therapy, psychology, mental health nursing, social work and teaching, and bring the skills and experience gained in these roles to their work as Registered Intermediaries.

40 The first and subsequent cohorts of MoJ Registered Intermediaries were trained by the authors at City University London.

41 Intermediary Procedural Guidance Manual (Home Office 2005) para 2.3.1.

42 The 2005 manual contains the Code of Ethics (39-40) and Code of Practice (44-42). The Codes have appeared in successive manuals.

43 Though initially described as 'a briefing note for the court': Home Office (n 41) para 3.9.11.

44 J Plotnikoff and R Woolfson, The Go-Between: Evaluation of Intermediary Pathfinder Projects (Lexicon 2007). 
the Registered Intermediary would intervene if a ground rule was breached. Ground rules hearings have become a requirement in cases involving Registered Intermediaries. ${ }^{45}$ Registered Intermediaries now routinely set the agenda for matters to be discussed at a ground rules meeting: ${ }^{46}$

i ground rules recommendations in the report (do's and don'ts for questioning);

ii the Registered Intermediary role and its neutrality;

iii how to address the witness (for instance, by their first name?) and how to address the Registered Intermediary;

iv if communication aids are to be used how that will be done;

v where the Registered Intermediary will sit in the live-link room so that he or she is visible on the TV screen, or if in court where they would sit so that they can see the witness and catch the eye of the judge if necessary;

vi when and where the Registered Intermediary will give the Registered Intermediary oath (in court and then go to the live-link room or from the live-link room?);

vii how the Registered Intermediary will signal to the judge a need to intervene if that becomes necessary (for instance, raising a hand and or interjecting 'Your Honour, could that be rephrased, please?');

viii timing of witness breaks (including how long and how often);

ix any other matters/residual queries.

Experience in England and Wales has shown that ground rules hearings must involve the judge, advocates and Registered Intermediary for the trial. If one of these is missing it will not be completely effective. It must be far enough ahead of the witness giving evidence to give the advocates an opportunity to plan questioning according to what was agreed at the ground rules hearing. It is therefore usually better for it to take place one or two days before the witness gives evidence. Detailed advice on conducting such a hearing is now available on line as a toolkit on the website of The Advocate's Gateway. ${ }^{47}$ The toolkit explains inter alia that this hearing is as much for the advocate as it is for the witness. When ground rules are agreed well enough in advance of the hearing, it allows the advocate properly to plan the questioning and the court to ensure that technical and practical issues are resolved in good time for when the witness gives evidence.

The first author's Registered Intermediary survey in 2009 suggested that Registered Intermediaries were having ground rules hearings in fewer than half their cases. ${ }^{48}$ In 2010 , after this finding was brought to the attention of the Criminal Procedure Rule Committee, the application form for a direction for special measures was amended. It now includes the words 'Ground rules for questioning must be discussed between the court, the advocates

45 See now Criminal Procedure Rules 2012, r 29.10, and the Application for a Special Measures Direction Form, Part F. See also Criminal Practice Directions [2013] EWCA Crim 1631, part 3E.

46 This list came from the first author's workshop with Registered Intermediaries in March 2012 at one of their twice yearly CPD events. In England and Wales the Application for a Special Measures Direction form, Part $\mathrm{F}$, simply refers to the purpose being 'to establish (a) how questions should be put to help the witness understand them, and (b) how the proposed intermediary will alert the court if the witness has not understood, or needs a break'. Registered Intermediaries have developed their own suggested agenda. 
and the intermediary before the witness gives evidence'. ${ }^{49}$ Subsequent survey data suggested that the frequency was increasing and they were occurring in approximately three-quarters of Registered Intermediary cases. ${ }^{50}$ It should be all. It is then of course vital that the ground rules made by the judge are followed; they were not made to be broken and the advocate's professional duty is to follow rules set by the judge. ${ }^{51}$

The intermediary will intervene if they believe a ground rule has been broken or if there is miscommunication in some other way and the trial judge upholds the intervention or not. The intermediary, if requested, will suggest alternative ways to put the question. Judges are used to ensuring that witnesses are questioned appropriately and it was clear from discussions that the authors had with members of the Northern Irish judiciary that they are understandably proud of their record in this respect. In England as well, of course, as further described below, judges are used to setting their own ground rules where necessary and then enforcing them. They recognise that there can come a time in difficult cases where they feel they can no longer intervene for fear that they will appear to have 'descended into the arena'. This illustrates a key benefit of having an intermediary at court for a vulnerable witness; they can intervene as often as is necessary. The judge decides whether or not to uphold the intervention, and maintains their traditional position of impartial 'umpire'.

Even with ground rules set, advocates do not always follow them and some may even take the attitude that they are made to be broken. ${ }^{52}$ One of the most challenging tasks of Registered Intermediaries is to get counsel to adapt their traditional form of crossexamination, and since 2004 there have been numerous incidents of advocates asserting their 'right' to ask leading or tag questions or to put their case in a particular way ${ }^{53}$ including on occasion in contravention of previously set ground rules. The tradition of barristers asserting their rights in cross-examination can be traced back to the $1700 \mathrm{~s} .{ }^{54}$ The very recent introduction of ground rules hearings based on intermediary reports represents a significant development; previously, the advocate prepared questions without detailed advice on a witness's communication needs and without the prospect of interventions from a specialist adviser on the witness's communication needs. Questioning a vulnerable witness is now recognised as a specialist skill and judges expect careful preparation and high standards from advocates. ${ }^{55}$

The innovation of the intermediary court report provides the judge with far more information regarding the vulnerable witness than is ordinarily available. The great advantage of the ground rules hearing in an intermediary case is that it is structured and transparent and based on the report. In Northern Ireland, where there is an intermediary this will apply to all witnesses, whether for the Crown or the defence, and to defendants. Advocates who are cross-examining will have had, in advance, a sounder basis for how to phrase their questions, although one cannot exclude the possibility that a fresh communication issue will arise during cross-examination. Adherence to judge-set ground

49 Criminal Procedure Rules 2012, r 29.10, and the Application for a Special Measures Direction Form, Part F.

50 Cooper (n 48).

51 See $R v$ Farooqi and Others [2013] EWCA Crim 1649: 'By way of emphasis, in the course of any trial, like everyone else, the advocate is ultimately bound to abide by the rulings of the court.' [109].

52 Cooper (n 48).

53 Anecdotal reports from Registered Intermediaries to the authors via email.

54 Hostettler says that barrister William Garrow played a 'pivotal role' in lawyers 'capturing the courtroom' and 'was a pioneer in using cross-examination as a means to comment on the evidence, refute or discredit the prosecution case and aggressively battle for the accused': J Hostettler, Fighting for Justice: The History and Origins of the Adversarial Trial (Waterside Press 2006) 15 and 41.

55 P Cooper, 'Witness Competency Hearings: A Test of Competence' (2013) (2) Criminal Bar Quarterly 5. 
rules is of such importance that the legal profession regulators should consider making it a professional conduct requirement to follow them.

\section{How the scheme works for prosecution witnesses}

The DoJ manual for Registered Intermediaries ${ }^{56}$ was developed from the material in the latest MoJ manual which is more detailed, prescriptive and helpful than it was when the MoJ WIS started. ${ }^{57} \mathrm{~A}$ comparison of the respective procedural guidance manuals demonstrates that the procedures are very similar in both jurisdictions.

When a Northern Ireland police officer identifies that the witness might benefit from the assistance of a Registered Intermediary the officer should speak to the Public Prosecution Service (PPS) to discuss the possible involvement of a Registered Intermediary (an 'early special measures meeting' or more likely a discussion over the phone). The police should obtain the necessary consents from the witness so that the Registered Intermediary in due course can look at relevant reports and speak, say, to the teacher, the social workers and doctor who know the witness. The police officer contacts the matching service ${ }^{58}$ and submits a request for service form. The ISS (Intermediaries Schemes Secretariat) matches a Registered Intermediary with suitable expertise who is available as required.

The Registered Intermediary conducts an assessment of the witness's communication abilities and needs. There is no set form for this; it depends on the specific witness and his or her abilities and needs. A responsible third party (not a witness in the case) must be present. It is best if this is the officer who will be conducting the ABE interview since it gives them additional insight into the witness's communication needs. The responsible third party is there in case any question subsequently arises over what took place. The Registered Intermediary provides a preliminary report for the police: either oral, if the interview takes place on the same day as the assessment, or in writing, if it takes place subsequently. The report assists the police officer in how to plan the interview, in terms of communication needs of the interviewee the layout of the room, etc. The Registered Intermediary assists during the interview, intervening if necessary to advise the police officer on communication. The Registered Intermediary then writes a report for the court based on their assessment, other information gathered about the witness, and what they learned about the witness's communication needs during the interview. The report is more than a summary of findings. It provides positive advice and examples to those who will question the witness about how most effectively to do it. It is this advice that is central to the formulation of questioning ground rules at court. The intermediary sends their report to the Investigating Officer (IO) and to the PPS for submission by the PPS with their application for a special measures direction.

In accordance with Practice Direction No 5/2011, each participant must ensure that all applications 'are made at the earliest possible opportunity' (2.1(i)) and, at the arraignment, the prosecution's legal representative must be in a position to tell the judge what applications will have to be made for special measures (3.7(a)). It follows that the arraignment would be the appropriate time to apply for the use of an intermediary. In any event, such an application must be heard at the 'earliest possible opportunity' in order to give the witness the maximum amount of time to know how they will be giving evidence in court and to give the other side ample opportunity to consider the contents of the report

56 The Registered Intermediaries Procedural Guidance Manual (Northern Ireland) V3 (DoJ 2013)

57 For instance, the third edition of the Intermediary Procedural Guidance Manual (MoJ 2012) now includes detailed notes on court reports, 32-43.

58 For the Northern Ireland pilot this will be the DoJ Intermediaries Schemes Secretariat, in England and Wales matching is now carried out by the Witness Intermediary Team at the National Crime Agency. 
and to plan their cross-examination accordingly. This is fair both to counsel who wants to do the best for the party who is instructing him or her and also for the witness. It is easy to forget that a witness who is asked questions they cannot deal with can become distressed because they realise that they are not helping the court in the way they would like to. The history of cases in England with vulnerable witnesses is littered with aborted trials because the vulnerable witness was too upset to continue. If the application is contested then the Registered Intermediary should attend the hearing in order to explain the report and its conclusions to the court. Obviously, they must be in court when the application is heard.

The Registered Intermediary assists in other ways. They attend the court familiarisation visit to assist with communication. They can advise the Witness Service or Young Witness Service as appropriate on matters relating to the witness's welfare of which the Registered Intermediary (who should not be seen as a witness supporter) may be aware. They can advise on timetabling of the witness's evidence ${ }^{59}$ and when and how the witness should watch their $\mathrm{ABE}$ interview to refresh their memory. One of the achievements of recent years is the recognition that the jury watches the taped interview as the evidence in chief but that the witness only watches it for memory refreshing. It is therefore not necessary for the witness to watch it at the same time as the jury, even though counsel and judges may initially react 'but we always do it this way'. In fact there are sound reasons why not: the witness may become tired or distressed or need breaks, all of which would disrupt the trial schedule. Far more sensible is for the witness to watch at an earlier time (not necessarily at their court familiarisation visit when a good deal of other information needs to be processed) and then for them to begin their cross-examination fresh the morning after the jury has watched the video. This recognition has now found its way into the Judicial College Checklist: Young Witnesses Cases ('consider whether child should watch DVD at a different time from jury') of January 2012.60

In practice the ground rules hearing is often on the day the witness is due to give evidence but for the reasons discussed above it is better for it to be at least the day before. It stands to reason that the intermediary must be part of the ground rules hearing, though, in the early days of the scheme in England and Wales, the intermediary was sometimes kept outside court while their report was discussed. This may have been because their role was not well understood and the intermediary was thought of as a witness, which of course they are not.

Immediately prior to the witness giving evidence the Registered Intermediary takes their oath and then assists as the witness gives evidence. They sit alongside the witness in the livelink room so that they are visible on the screen (or stand or sit next to the witness if they are giving evidence in court) in order to monitor communication. They intervene during questioning when appropriate and as often as appropriate in accordance with the ground rules and the recommendations in their report. For Northern Ireland, the MoJ Code of Practice and Code of Ethics for Registered Intermediaries has been replicated. ${ }^{61}$ Applications for an intermediary for witnesses and defendants are made under Crown Court Rules, ${ }^{62}$ which include provision for the intermediary oath. ${ }^{63}$

Since 2005, at first through a secure online forum known as the 'SmartSite', now via Registered Intermediaries Online (RIO), Registered Intermediaries in England and Wales

59 For example, that the witness would be at their best first thing in the morning and would not be able to give comparably good evidence if it came at the end of several hours' waiting at court.

60 The important thing is that they have the opportunity to refresh their memory from it before they are crossexamined: Judicial College Bench Checklist: Young Witness Cases (Judicial College 2012).

61 Email from the DoJ to the authors, 26 April 2012.

62 Crown Court (Amendment) Rules (Northern Ireland) 2013 (2013 No 82).

63 DoJ briefing paper to the Northern Irish Judiciary, November 2012. 
have been able to discuss cases and issues amongst themselves and receive information from the MoJ. A study in 2011 analysed what could be learned from these online postings:64

- Registered Intermediary tasks have extended beyond the investigative interview and trial. For example, they have assisted at identification procedures and beyond their statutory remit their value has been recognised in family cases and for vulnerable defendants;

- some of the problems emerging at the trial stage, such as a witness's inability to read their written statement, are as a consequence of the police failing to involve a Registered Intermediary at the investigative interview;

- the Registered Intermediary's role is not always understood by some justice system practitioners. The Registered Intermediary is not an expert witness. Their report is not evidence in the case;

- even when there is a ground rules hearing, some advocates find it difficult or seem unwilling to adapt their questioning to ensure it is appropriate to the communication needs of the witness.

The DoJ has provided a similar online forum which should prove to be a rich source of support for its intermediaries.

\section{The route to best evidence}

On 12 May 2009, the Lord Chief Justice of Northern Ireland wrote to judges about the way in which young and vulnerable witnesses and victims are dealt with. The main points were:

- they should not attend court on the first day of trial;

- the child should be asked to be in the TV link room at 10.30am on the second day of trial unless the case is being opened on the second day, in which case a timetable needs to be discussed;

- the child should be introduced to the court environs and Crown counsel should consult with the child. Both should happen prior to the hearing and 'well before the date fixed for hearing';

- the judge should ask the court staff to test the equipment prior to the trial starting and on the morning well in advance of the court starting;

- the above should be adopted for other vulnerable witnesses or victims; and

- Every effort should be made to bring certainty to the timing of their evidence. That can only assist in the delivery of reliable evidence and the administration of justice.'

In May 2011 The Experiences of Young Witnesses in Criminal Proceedings in Northern Ireland ${ }^{65}$ was published. The statistics showed that more could be done to improve these experiences. For instance:

- only 48.6 per cent had had a pre-trial visit at all;

- the mean time between reporting the offence and trial was 18.1 months in the crown court; only 42 per cent had their trial happen on the first scheduled date (versus 65 per cent in England); 17 per cent had it rescheduled three or

$64 \mathrm{~J}$ Plotnikoff and R Woolfson, Registered Intermediaries in Action: Messages for the CJS from the Witness Intermediary Scheme SmartSite (Ministry of Justice/NSPCC 2011). At that stage there were 112 active Registered Intermediaries on the national database for the WIS.

65 D Hayes, L Bunting, A Lazenbatt, N Carr and J Duffy, The Experiences of Young Witnesses in Criminal Proceedings in Northern Ireland (Queen's University Belfast/NSPCC 2011). 
more times; average waiting time at the crown court was 12.7 hours (versus 5.8 hours in England); only 30 per cent completed their evidence on the first day (versus 67 per cent in England); and only 8 per cent began their evidence in the morning of the first day of court attendance;

- only 54 per cent had been kept informed prior to trial about what was happening with the case;

- 62.7 per cent saw the defendant during the course of the trial.

In terms of memory refreshing, of the 13 young witnesses who had given a video interview, seven saw it on the morning of the trial, three in the week before the trial and two were not shown it before the trial started. Complaints about questioning were that they were: repetitive (77.1 per cent); too long or complicated (45.7 per cent); jumped around in time (34.3 per cent); placed unrealistic demands on memory (31.4 per cent); and too fast (11.4 per cent).

Although the majority of young witnesses felt they had been able to tell the court everything they wanted to say and had understood the questions, 42.9 per cent $(n=15)$ reported not understanding some of the questions asked and that many who had difficulties felt unable to tell the judge they had a problem. The report concluded that the use of intermediaries is likely to be 'of particular value to this group as well as young witnesses generally, and should be brought forward as soon as possible'. In the study 62.2 per cent indicated that they would be willing to give evidence in a criminal trial again if asked but 51.4 per cent stated that there was nothing positive about the experience of being a witness.

Areas flagged up for improvement included better pre-trial contact and informationsharing between parents and criminal justice agencies which in turn would lead to implementation where necessary of special measures, more frequent practising with the live link, avoiding delay, re-issuing the Lord Chief Justice's recommendations of 2009, bringing forward 'as soon as possible' the introduction of intermediaries and developing guidance and training initiatives for judges and legal professionals in handling vulnerable witnesses. The introduction of Registered Intermediaries in Northern Ireland could herald a legal culture change in respect of vulnerable witnesses as it did in England and Wales. The rollout of Registered Intermediaries across all 43 police force areas in England and Wales was shortly followed by landmark case law. Whether this is a coincidence or whether Registered Intermediaries were a catalyst is a moot point; the fact is it has happened. The English Court of Appeal has repeatedly scotched any notions that counsel has free-rein in the crossexamination of a vulnerable witness. Some but not all these cases had intermediary involvement.

The Court of Appeal in England and Wales has begun to consider not only the appropriate questioning for vulnerable witnesses but also how the defendant can have a fair trial if his or her counsel did not put the defence case to the witness in the traditional way. The emerging view is that the questioning should be adapted to the witness, and so long as the jury is not misled and is provided with information about any inconsistencies in the accounts given by the witness, the trial process remains fair. It is not necessary that the 'putting of inconsistencies' forms part of the cross-examination. Whether adopting this approach will require a culture change in Northern Ireland remains to be seen. If so, it is something they have in common with their counterparts in England and Wales.

The watershed case was $R v B^{66}$ where the complainant/witness was four years old and was giving evidence of sexual abuse which had taken place when she was less than three years old. There was no intermediary and counsel was left to his own devices in phrasing 
the questions. On appeal counsel submitted that attempts to cross-examine the child were futile; because of her age he was unable effectively to challenge her account and to put the defendant's case to her. In his judgment, the Lord Chief Justice made clear that 'none of the characteristics of childhood, and none of the special measures which apply to the evidence of children carry with them the implicit stigma that children should be deemed in advance to be somehow less reliable than adults'. ${ }^{67}$

The trial process though must cater 'for the needs of child witnesses, as indeed it has increasingly catered for the use of adult witnesses whose evidence in former years would not have been heard, by, for example, the now well understood and valuable use of intermediaries' and:

it should not be over-problematic for the advocate to formulate short, simple questions which put the essential elements of the defendant's case to the witness, and fully to ventilate before the jury the areas of evidence which bear on the child's credibility. Aspects of evidence which undermine or are believed to undermine the child's credibility must, of course, be revealed to the jury, but it is not necessarily appropriate for them to form the subject matter of detailed crossexamination of the child and the advocate may have to forego much of the kind of contemporary cross-examination which consists of no more than comment on matters which will be before the jury in any event from different sources.

Four months after the judgment in $B$, two ten-year-old boys stood trial at the Old Bailey for the rape of an eight-year-old girl. Again, there was no intermediary either for the complainant or for the defendants. The 'ground rule' was that the girl should only be questioned for 45 minutes in the morning and for 45 minutes plus 15 minutes in the afternoon. The Court of Appeal judgment in $R v W$ and $M^{68}$ does not say how that ground rule came to be decided. The questioning as set out in the judgment contains tag questions ('S did not pick you up at any time, did he?'); multi-parted questions ('Do you want to think about that one again? No one is going to be cross with you.'); and comment ('Little bit naughty but do not worry. Nothing too terrible.'). The judge wanted to replace assertions with open questions. The submission of no case to answer, like the submissions in the Court of Appeal, was based on answers from the child which 'had been the result of questions in which a proposition had been directly put to the child, usually with an invitation to agree'. The court stated:

It is particularly important in the case of a child witness to keep a question short, and even more important than it is with an adult witness where it also matters to avoid questions which are rolled up and contain, inadvertently, two or three at once. It is generally recognised that particularly with child witnesses short and untagged questions are best at eliciting the evidence. By untagged we mean questions we [sic] do not contain a statement of the answer which is sought. ${ }^{69}$

One of the most challenging prosecution cases put before a jury was in the case of $R v$ Watts, ${ }^{70}$ where there were four complainants. Three of them suffered from cerebral palsy. One could not communicate save by shouting, spitting and swearing when distressed. A second could only indicate 'Yes' or 'No' by the movement of her eyes. A third could answer questions by use of a computer device attached to her chair. The fourth suffered a stroke between her ABE interview and the trial and was then incapable of any form of communication. Counsel for the appellant submitted in effect that because of the

67 [2010] EWCA Crim 4 [40].

68 [2010] EWCA Crim 1926.

69 Ibid [30].

70 [2010] EWCA Crim 1824. 
unsatisfactory nature of the evidence, the verdicts were unsafe 'even if some logical basis for the verdicts can be discerned'. However, the Court of Appeal found that:

even in a case of difficulty and complexity such as this, the primacy of the jury in our criminal justice system has to be respected, particularly where matters of reliability and the assessment of witnesses lie at the centre of the case ... The ordinary principles governing criminal trials require both the judge and the jury to face the realities which can sometimes arise where special measures are put in place, but these arrangements do not alter the principle that the primacy of the jury should be respected. ${ }^{71}$

Two of the witnesses would have given their evidence with the assistance of an intermediary but defence counsel elected not to cross-examine them. More recently, there have been two cases in which the Court of Appeal upheld a trial judge's decision to impose his own rules on the manner of cross-examination of a child. In $R v E{ }^{72}$ the complainant was five at the time of the alleged assault. The trial judge told defence counsel that he intended to tell the jury that during the cross-examination of the child the traditional form of cross-examination would not occur and instead would be restricted to asking necessary questions. Defence counsel should not ask questions challenging the girl. During the crossexamination the judge interrupted counsel and told him to ask open questions rather than to make suggestions because it would be difficult to know whether the girl was giving accurate answers or just agreeing with counsel. Counsel then asked ten listed questions. The Court of Appeal concluded that the judge had been right to seek to avoid a situation where counsel confronted the child with assertions; that risked confusion in the mind of the witness and it was difficult to see how the right to a fair trial had been compromised simply because the defendant had not been able to ask, 'S didn't punch you, did he?'. The judgment in $E$ still leaves room for debate about which witnesses cross-examination restrictions should be applied to, what the specific restrictions should be and the timing and the content of the advice to the jury in such circumstances.

The Court of Appeal similarly dismissed an appeal in $\mathrm{R} v \mathrm{Will}^{73}$ and endorsed the judge's decision to place limitations on the cross-examination of the child complainant witness. Counsel submitted that although he had adopted the judge's approach, his codefending counsel adopted a more 'traditional' type of cross-examination, albeit the judge intervened to stop the long questions and inappropriate comment. It was held that, where it is necessary and appropriate to have limitations on the way in which the advocate conducts cross-examination there is a duty on the judge to ensure that those are complied with. The case highlighted that:

for vulnerable witnesses, the traditional style of cross-examination where comment is made on inconsistencies during cross-examination must be replaced by a system where those inconsistencies can be drawn to the jury at or about the time when the evidence is being given and not in long or complex cases for that comment to have to await the closing speeches at the end of the trial.

Judges are also assisted by the Crown Court Bench Book and the new Judicial College Bench Checklist: Young Witness Cases ('How defence case is to be put. For younger children, inform jury of evidence believed to undermine credibility, but do not necessarily address in detailed cross-examination.'). ${ }^{74}$ It is within the knowledge of the authors that trial judges follow the

71 [2010] EWCA Crim 1824 [54].

72 [2011] EWCA Crim 3028.

73 [2011] EWCA Crim 1938.

74 Judicial College (n 60). 
example in Wills of informing the jury of any inconsistencies of account directly after the child has given their evidence.

MoJ statistics ${ }^{75}$ in 2012 revealed that there had been over 5300 requests for a Registered Intermediary since the scheme was first implemented as a pilot project in 2004. Of that number (as at 31 March 2012), 3318 have been made since August 2009. Of the 3318 requests received at 31 March 2012, 3160 (94.95 per cent) were matched, 70 (2.10 per cent) were unmatched, ${ }^{76} 93$ (2.80 per cent) were cancelled and 5 ( 0.15 per cent) were in progress at the time of the statistics being published (that is they overlap from one month to the next). Despite intermediary involvement in thousands of cases in England and Wales since 2004 there has been only one appeal on the basis that the Registered Intermediary thwarted a fair process. The Court of Appeal in 2013 rejected any challenge to the work done by the Registered Intermediary in that case, however, it criticised the length and style of crossexamination and noted that counsel 'failed sufficiently to adapt their questions in order to take account of [the deaf witness's] difficulties in communication'. ${ }^{77}$

Over the six-month period from September 2012 to February 2013, an average of 122 requests per month were received by the MoJ for the services of a Registered Intermediary. The majority were for prosecution victims, some were for prosecution witnesses, one was for a defence witness. ${ }^{78}$ Although the 1999 Act provides for the use of intermediaries for both prosecution and defence witnesses they have scarcely been used for defence witnesses. This may be on account of a low level of awareness about eligibility amongst defence solicitors in England and Wales. There should be greater awareness in Northern Ireland where defence solicitors are far more likely to be aware of the scheme because of its applicability to vulnerable defendants. At the time of writing the ISS has received requests for a Registered Intermediary for both suspects and defendants but not for defence witnesses. ${ }^{79}$

In the case of a defence witness it would be the defence solicitor who would identify the fact that the witness may need assistance from a Registered Intermediary. It is the solicitor who would have to obtain the necessary consents, contact the matching service, act as the responsible third party (or arrange for one) in the assessment and deal with the Registered Intermediary. In terms of assessment, report-writing, ground rules hearing and assistance during evidence, the Registered Intermediary's role is the same as with a prosecution witness. ${ }^{80}$

\section{Defendants}

The concern about 'vulnerable witnesses' since 1988 has centred on prosecution witnesses and, in particular, victims of crime. When the then Home Secretary introduced the Bill which became the 1999 Act (and the 1999 Order), he spoke only of victims: 'We must re-establish the system so that proper dignity and respect are given to the victim and to the community.'

75 Vulnerable and Intimidated Witnesses Section, Victims and Witnesses Unit, Justice Policy Group, Ministry of Justice, London, by email to the first author, 24 April 2012.

76 Reasons for a request being unmatched include a combination of factors such as not being able to identify a suitable, available Registered Intermediary prepared to accept the work in the specified geographic area, the request being made at too short notice and incorrect information being submitted by the requestor.

77 In $\mathrm{R} v$ LA and Others [2013] EWCA Crim 1308 [64].

78 WIS Usage Statistics provide by Jason Connolly (MoJ) by email to the first author, 7 March 2013. A year later the average monthly figure for the corresponding period is just over 200 per month (MoJ email to the authors, March 2014).

79 Information supplied by the DoJ by email to the authors, March 2014.

$80 \mathrm{MoJ}$ (n 57) 18, 20. 
In 2005, the House of Lords, in R $v$ Camberwell Green Youth Court, ${ }^{81}$ held that the special measures regime was not incompatible with the Human Rights Act because prosecution witnesses could take advantage of it but defendants could not. However, studies have shown that a substantial number of defendants have conditions which cause them to have limited language ability and communication skills, learning disabilities, and to be acquiescent and suggestible: ' $16 \%$ of people placed in custody meet one or more of the assessment criteria for mental disorder 82 and 'a consensus figure of $50-60 \%$ of young people who are involved in offending having speech, language and communication needs is emerging, ${ }^{83}$

A recent report found that 'while the numbers of defendants who might be considered vulnerable is relatively high it was extremely rare to see defendants make an application for, or use any kind of special measure'. ${ }^{84}$ Section 47 of the Police and Justice Act 2006 enabled a court to make a direction allowing an accused to give evidence by live link in England. In Northern Ireland, a similar provision is made by Article 21A of the 1999 Order, as inserted by Article 82 of the Criminal Justice (Northern Ireland) Order 2008 (No 1216 (NI 1)), which was subsequently substituted by Article 19 of the Justice Act (Northern Ireland) 2011. The report also noted the imminent arrival of intermediaries and said that the inspectors 'express the clear hope that their use will ultimately extend beyond the courtroom to become commonplace in the investigative setting, as is being planned'. ${ }^{85}$ The police will also need training in the use of Registered Intermediaries; findings included that 'special measures are not being identified at the early stages and many [Police] Officers do not have sufficient understanding of special measures to explain these appropriately to victims and witnesses' ${ }^{86}$

Article 21BA of the 1999 Order, as inserted by Article 12 of the Justice Act (Northern Ireland) 2011, as amended by s 11 of the Criminal Justice Act (Northern Ireland) 2013 (c 7), provides for examination through an intermediary of a vulnerable accused giving testimony. Both Articles 21A and 21BA employ the same criteria:

(i) Where the accused is aged under 18 when the application is made, the condition is that the accused's ability to participate effectively in the proceedings as a witness giving oral evidence in court is compromised by the accused's level of intellectual ability or social functioning

(ii) Where the accused has attained the age of 18 when the application is made, the conditions are that (a) the accused suffers from a mental disorder (within the meaning of the Mental Health (Northern Ireland) Order 1986) or otherwise has a significant impairment of intelligence and social functioning; and (b) the accused is for that reason unable to participate effectively in the proceedings as a witness giving oral evidence in court.

The contrast with the test in Article 4 is obvious: 'ability to participate effectively in the proceedings' as opposed to 'the quality of evidence' is likely to be diminished'. The expression 'in order to be able to give their best evidence' does not apply by statute to

81 [2005] UKHL 4.

82 M Maguire, Not a Marginal Issue: Mental Health and the Criminal Justice System in Northern Ireland (CJINI 2010).

83 J Gregory and K Bryan, 'Speech and Language Therapy Intervention with a Group of Persistent and Prolific Young Offenders in a Non-custodial Setting with Previously Undiagnosed Speech, Language and Communication Difficulties' (2011) 46(2) International Journal of Language and Communication Disorders 202-15.

84 CJINI, The Use of Special Measures in the Criminal Justice System in Northern Ireland (CJINI 2012) para 3.18

85 Ibid 4.13 .

86 Ibid para 3.30. 
defendants. There is a parallel provision in the Coroners and Justice Act 2009 but it has never been brought into effect. ${ }^{87}$ Judges in England and Wales face applications by defence counsel to adapt the court proceedings in order to assist the defendant without any effective statutory guidelines. Where they allow defendants to be assisted by an intermediary, the order is based on the court's inherent jurisdiction to ensure that the defendant has a fair trial, pursuant to Article 6 of the European Convention on Human Rights. The power to do this was noted by Baroness Hale in her speech in the Camberwell Green Youth Court case. ${ }^{88}$ However, procedures are undocumented, $a d$ hoc and funding is a constant source of difficulty. 89

Northern Ireland's scheme for defendants is leading the way as the first of its kind anywhere. We can look forward to seeing the courts establish best practice when dealing with applications for an intermediary for a defendant. In England and Wales, most cases where the judge has made an order allowing for the use of an intermediary to assist a defendant have included allowing the intermediary to assist throughout the trial. This has been successful in making sure that the defendant has understood the trial process as it went along. It has inevitably put a strain on resources.

The Court of Appeal in $\mathrm{R} v \operatorname{Cox}^{90}$ considered a case where a judge had felt that the defendant needed assistance from an intermediary but none could be found. The trial took place regardless, with the trial judge making important adjustments to the trial process in order to accommodate the defendant's needs. It was found that 'when every sensible step taken to identify an available intermediary has been unsuccessful, the next stage is not for the proceedings to be stayed, which in a case like the present would represent a gross unfairness to the complainant, but for the judge to make an informed assessment of whether the absence of an intermediary would make the proposed trial an unfair trial'. ${ }^{91}$ Since the Justice Act (NI) 2011 makes no reference to assistance from an intermediary other than when giving evidence, the DoJ scheme will not allow for an application for special measures other than when giving evidence. Of course, that does not prevent the judge from making any adjustments to the trial process to assist the defendant, including the use of an appropriate adult.

It is also anticipated that intermediaries can assist vulnerable defendants in the police station during their interview under caution. ${ }^{92}$ There is no established procedure for this in England and Wales, thus the procedural guidance has been written from a theoretical perspective. The Northern Ireland Registered Intermediaries Procedural Guidance Manual suggests that the third party when the Registered Intermediary carries out her assessment should be the defence solicitor. ${ }^{93}$ Whether or not the assessment is taking place in a police station, it would be inappropriate for a police officer to be present during the assessment. The vulnerable defendant needs to feel comfortable if disclosing private and possibly highly sensitive information about his communication needs or disabilities. An intermediary

87 S 104 of the Coroners and Justice Act 2009 inserts s 33BA into the 1999 Act which contains this provision for defendant intermediaries in England and Wales.

88 R v Camberwell Green Youth Court [2005] UKHL 4 [59].

89 P Cooper and D Wurtzel, 'A Day Late and a Dollar Short: In Search of an Intermediary Scheme for Vulnerable Defendants in England and Wales' (2013) (1) Criminal Law Review 4-22.

90 [2012] EWCA Crim 549.

91 Ibid [30].

92 It is arguable that the legislation does not cover this and only applies to defendants at court when giving testimony. Such an interpretation would create a stark disparity with vulnerable prosecution witnesses who can benefit from an intermediary at the police station not just at court when giving testimony. A narrow interpretation for vulnerable defendants would potentially deprive the police and the defendant of vital assistance at a crucial stage in the investigation.

93 Registered Intermediaries Procedural Guidance Manual (n 56) para 1.38. 
assessment is not a situation where a defendant is or ought to be under caution. Clearly, a defendant would have to consent to the Registered Intermediary disclosing to the police information about his communication needs. Defence solicitors may need to explain to their clients that the point of intermediary involvement at this stage is to allow the interviewing officer to adapt their questioning and understand the answers, both of which are as much for the benefit of their client as they are for the benefit of the police.

Anything said about the offence itself is another matter. It is the view of the authors, which they conveyed to the delegates they trained on behalf of the DoJ, that anything said by the defendant about the offence should be kept confidential and disclosed to defence solicitors but not to anyone acting on behalf of the Crown. ${ }^{94}$ This contrasts with their duty, when assisting a prosecution witness, of disclosing to the IO or the PPS anything said by or about the witness which might potentially undermine their evidence or the prosecution case. In this way intermediaries finds themselves adjusting their duties in accordance with the very different rules regarding disclosure which apply to the Crown and to the defence. When questioning defendants, time is of the essence in a way in which it is not for the prosecution witness on account of the custody time limits. The procedural guidance states: 'If an officer needs to interview a witness/suspect as a matter of urgency, and before a Registered Intermediary is available, then they should record the reasons for this and notify the PPS and defence legal representative, if applicable. 95

There is some overlap with the role of the appropriate adult; experience will reveal how the two roles work together. Will the interview suite become overcrowded with the suspect, two interviewers, a Registered Intermediary and the solicitor? If there is an appropriate adult too will there be room and, in any event, which room? Registered Intermediaries have been warned that the ambiance of the typical suspect interview room with bolted down furniture is quite different from an $\mathrm{ABE}$ interview suite. What will happen if the intermediary recommends a different environment because it would be more conducive to communication with the vulnerable defendant? The interviewing officers may not be trained in how to interview a vulnerable person. The ABE procedure does not apply to the suspect. The PEACE ${ }^{96}$ model of interviewing is meant to be similar in structure to an $\mathrm{ABE}$ interview but its purpose is different and the Registered Intermediary may find that suspect interviewers are less experienced in adapting their questioning for vulnerable defendants.

At court, DoJ Registered Intermediaries are available for when the defendant gives testimony. Since defence counsel might only make a firm decision about whether to call the defendant just before the close of the prosecution case it is unclear when the application for special measures should be made for the defendant intermediary. Should it be prior to the trial as a contingency application or should it be left until defence counsel is certain? Will the intermediary be available at short notice to carry out an assessment and act at trial if necessary? Defence counsel is unused to revealing anything about the defendant before the trial begins, on the other hand, if prosecution counsel is suddenly faced with an intermediary report setting out prescriptively how a defendant is to be questioned, they may legitimately ask for time to consider their cross-examination. The project evaluation may establish best practice.

94 Registered Intermediaries Procedural Guidance Manual (n 56) 'Principles of RI practice' para 1.15.

95 Ibid para 1.41.

96 This PEACE model is a mnemonic acronym for the sequential phases of the model. For a review of its effectiveness, see D Walsh and R Bull 'What Really is Effective in Interviews with Suspects? A Study Comparing Interviewing Skills against Interviewing Outcomes' (2010) 15 Legal and Criminological Psychology 305-21. 
If a judge believes that the defendant needs communication support throughout other parts of the trial so that he or she may participate effectively, the advice from the DoJ is that:

he may be assisted by a court defendant supporter. Where no other appropriate person is available to perform this role (for example, a family member or carer), the Department has put arrangements in place, for the purpose of the pilot schemes, for Mindwise (who deliver the Appropriate Adult Scheme) to act as a court defendant supporter. ${ }^{97}$

A judge might consider that what a supporter can do is more limited than what an intermediary can, and might even consider ordering an intermediary for the defendant for the whole of the trial. That would have significant resource implications for the scheme as a whole which could not be ignored.

\section{Briefing the Bar and the judiciary}

In 2011, Plotnikoff and Woolfson produced a progress report on the experience of young witnesses in the criminal courts. ${ }^{98}$ Top of the list of challenges was appropriate questioning at court. There have been regular and repeated calls for specialist training for advocates. ${ }^{99}$ On 13 May 1999 at a Childline conference, representatives of the Bar 'acknowledged the need for training for barristers on matters such as the tone and manner of crossexamination'. 100 Twelve years later, in April 2011, the Advocacy Training Council (ATC) published its Raising the Bar report. ${ }^{101}$ It cited as one of its strongest themes, the 'urgent need to address the significant problems associated with vulnerable people in the Court system'. It accepted that the handling and questioning of vulnerable witnesses, victims and defendants is indeed a specialist skill and should be recognised as such by practitioners, judges, training providers and regulators. Some Bar training has been delivered over the years by the authors, including participative training by the second author. A 'vulnerable witness' module was introduced in 2011 at the highly regarded South Eastern Circuit Advanced Advocacy Course held annually at Keble College but only about 70 barristers a year take part in this. The ATC now supports The Advocate's Gateway project which places online the latest law and guidance to assist judges and advocates in cases with vulnerable witnesses or defendants. ${ }^{102}$

With the advantages of a smaller and more cohesive Bar, training in Northern Ireland should be easier. Perhaps the Northern Ireland Bar will introduce compulsory continuing professional development (CPD) training on the handling of vulnerable witnesses

97 DoJ briefing paper to the NI Judiciary (November 2012).

98 J Plotnikoff and R Woolfson, Young Witnesses in Criminal Proceedings: A Progress Report on Measuring up? (Nuffield Foundation/NSPCC 2011).

99 For example, R Flin, R Bull, J Boon and A Knox, 'Child Witnesses in Scottish Criminal Trials' (1993) 2 International Review of Victimology 309-29, 327; M R Kebbell, C Hatton, S D Johnson and C M E O’Kelly, 'People with Learning Disabilities as Witnesses in Court: What Questions Should Lawyers Ask?' (2001) 29 British Journal of Learning Disabilities 98-102; H L Westcott, 'Child Witness Testimony: What Do We Know and Where Are We Going?' (2006) 18(2) Child and Family Law Quarterly 174-90; B O’Mahony, 'The Emerging Role of the Registered Intermediary with the Vulnerable Witness and Offender: Facilitating Communication with the Police and Members of the Judiciary' (2009) 38 British Journal of Learning Disabilities 232-37; A Keane, 'Cross-examination of Vulnerable Witnesses: Towards a Blueprint for Professionalisation' (2010) 16(2) (175) International Journal of Evidence and Proof 181-86; and Youth Justice Working Group, Rules of Engagement: Changing the Heart of Youth Justice (CSJ 2012).

100 K McEwan, 'In Defence of Vulnerable Witnesses: The Youth Justice and Criminal Evidence Act 1999' (2000) 4(1) International Journal of Evidence and Proof 1-30, 20.

101 Advocacy Training Council, Raising the Bar: The Handling of Vulnerable Witnesses, Victims and Defendants in Court (ATC 2011).

102 See < www.theadvocatesgateway.org> co-founded by the first author, J Plotnikoff and R Woolfson. 
(including working with intermediaries), consider the question of 'ticketing' (i.e. accrediting advocates to work with vulnerable witnesses and defendants) and create its own version of The Advocate's Gateway? In any event, training for lawyers is essential. Some has occurred already. For instance, in May 2012 the Criminal Bar Association held an annual conference on Victims and Vulnerable Witnesses in the Criminal Process at Queen's University; the Judicial Studies Board hosted a seminar 'Judges and Intermediaries' in December 2012 which was attended by some 20 Belfast judges and intermediary seminars were delivered to police and prosecutors in April 2013. ${ }^{103}$ It is only through participative training that advocates really begin to realise and to practise the specialist skills required to question vulnerable witnesses.

\section{Civil cases}

There is ample scope for intermediaries to be used in civil cases. ${ }^{104}$ A number of English family court cases have included discussion and sometimes use of an intermediary for a vulnerable witness. In one the judge noted that the absence of a statutory intermediary scheme in family cases led to 'real obstacles'. ${ }^{105}$ Notwithstanding, there are Family Justice Council Guidelines in Relation to Children Giving Evidence in Family Proceedings encouraging practitioners to consider the use of intermediaries at the 'earliest opportunity'. ${ }^{106}$ More recently, in the High Court in England and Wales, a father's appeal against a fact-finding decision was successful on the ground that inadequate special measures were in place when he gave evidence ${ }^{107}$ and at the rehearing he was assisted by an intermediary. In another, a highly vulnerable young woman was assisted by an intermediary to give evidence about previous sexual abuse. ${ }^{108}$

A 2011 Northern Ireland Law Commission report ${ }^{109}$ recommended the use of special measures $^{110}$ in the civil courts for children, or people who are living with mental illness, learning disability or personality disorder or physical disability or disorder, and for witnesses who suffer fear and distress in connection with giving evidence. Children should be automatically entitled to use the live link unless the use of that will not be likely to maximise the quality of their evidence. The Commission, 'encouraged by the use of intermediaries in criminal proceedings in England and Wales', recommends that the use of intermediaries is included as a special measure subject to it being successfully implemented in criminal proceedings in Northern Ireland. ${ }^{111}$ Northern Ireland might be the first to introduce a scheme of Registered Intermediaries for the civil courts.

103 The authors and Northern Ireland Registered Intermediaries spoke at these events.

104 P Cooper, 'Child Witnesses in Family Proceedings: Should Intermediaries be Showing Us the Way?’ (2011) 41 (April) Family Law 397-403; A Brammer and P Cooper, 'Still Waiting for a Meeting of Minds: Child Witnesses in the Criminal and Family Justice Systems' (2011) 12 Criminal Law Review 925-941; and P Cooper, 'ABE Interviews, Children's Testimony and Hearing the Voice of the Child in Family Cases: Are We Barking up the Right Tree?' in M Thorpe and W Tyzack (eds), Dear David: A Memo to the Norgrove Committee from the Dartington Conference (Jordans 2011) 23-31.

$105 \operatorname{Re} X$ (A Child) [2011] EWHC 3401 (Fam) [42]

106 Working Party of the Family Justice Council, Guidelines in Relation to Children Giving Evidence in Family Proceedings (Family Justice Council 2011) para 14.

107 Re M (Oral Evidence: Vulnerable Witness) [2012] EWCA 1905.

$108 \operatorname{Re} A$ (A Child) (Vulnerable Witness: Fact Finding) [2013] EWHC 2124 (Fam), includes a detailed description of how the vulnerable witness testimony was heard with the assistance of special measures including an intermediary.

109 NILC, Vulnerable Witnesses in Civil Proceedings (NILC 10, 2011)

110 The range of special measures would be the same as those used in the criminal courts including the use of intermediaries.

111 NILC (n 109) 62, para 3.52. 


\section{Conclusions}

If England and Wales are indicative, then the extent to which Northern Ireland's crossexamining culture changes to accommodate the needs of the vulnerable is primarily in the hands of the Registered Intermediaries, trial judges and the Court of Appeal. Northern Ireland's intermediary legislation closely mirrors that which has been in force in England and Wales for almost ten years for prosecution and defence witnesses. Much has been learnt since the first MoJ Registered Intermediaries were recruited. The DoJ Registered Intermediaries have the advantage of the springboard of existing Registered Intermediary training, procedural guidance and research showing the vital importance of ground rules being set and enforced by judges and their wide-ranging role, including assisting with communication during witness familiarisation and memory refreshing. The DoJ has been able to take advantage of $\mathrm{MoJ}$ 'learning through doing' resulting in advances in training and guidance for its Registered Intermediaries. The DoJ's Registered Intermediary course and its procedural guidance manual are the most detailed and practical to date. Similarly, following in the footsteps of the MoJ, the DoJ regulates and supports the Northern Ireland Registered Intermediaries. The DoJ is also supporting their attendance at the regular MoJ Registered Intermediary CPD events which promulgate best practice.

The DoJ will deliver an evaluation report in 2015 and one of the most eagerly awaited aspects will be the analysis of the brand new scheme available for vulnerable defendants at the police station and when they give testimony. As at March 2014 only four requests for intermediaries for vulnerable defendants have been made and further awareness raising may be required amongst defence solicitors. ${ }^{112}$ If and when an application for a defendant Registered Intermediary is made it will be the first ever under a statutory scheme. Apart from dealing with applications for a Registered Intermediary for vulnerable defendants when giving evidence, judges will no doubt be asked to determine how to ensure the effective participation of the defendant for the rest of the trial. Will judges order that the Registered Intermediary be present for the rest of the trial and, if so, who will fund this? Experience in England and Wales suggests that this may be an issue and there may be challenges to Northern Ireland's defendant scheme on the basis that it does not go far enough to ensure that the vulnerable defendant understands all of the court proceedings (not just if and when he gives oral evidence) in order to effectively participate.

In September 2011 the then Lord Chief Justice of England and Wales commented extra-judicially:

The use of intermediaries has introduced fresh insights into the criminal justice process. There was some opposition. It was said, for example, that intermediaries would interfere with the process of cross-examination. Others suggested that they were expert witnesses or supporters of the witness. They are not. They are independent and neutral. They are properly registered. Their responsibility is to the court ... their use is a step which improved the administration of justice and it has done so without a diminution in the entitlement of the defendant to a fair trial. ${ }^{113}$

112 Already this has included conference presentations, distribution of information leaflets and in 2013 there have been two articles about the scheme in The Writ (by N Dempster and the second author) and a further is in print (by the first author).

113 'Vulnerable Witnesses in the Administration of Criminal Justice', The Rt Hon The Lord Judge, Lord Chief Justice of England and Wales, 7 September 2012, at the 17th Australian Institute of Judicial Administration Conference. 
Time will tell if Northern Ireland's Lord Chief Justice will heap similar praise, either in court or outside it, on the DoJ's Registered Intermediaries. It is more likely to be so if there is participative training for Northern Ireland's police, lawyers and judges and a thoroughly evaluated pilot. The use of intermediaries in Northern Ireland would be immediately more effective if court rules made ground rules hearings mandatory as is now the case in England and Wales. It would be better still for the administration of justice if Northern Ireland's advocates underwent training to be 'ticketed' for vulnerable witness cases and if their regulator made it a requirement of the code of conduct to follow ground rules; neither of these things has happened yet in England and Wales. Going second has already proved to be an advantage, but Northern Ireland could do even more to further capitalise on the lessons from the Registered Intermediary scheme in England and Wales. 
